\title{
INTERACTION BETWEEN NATIONAL ACCOUNTS AND SOCIO-ECONOMIC POLICY
}

\author{
By Steven Keuning \\ Statistics Netherlands
}

\begin{abstract}
An important application of national accounts is in the formulation of socio-economic policy. This paper starts out with a discussion of the current situation in the Netherlands. Subsequently, it identifies several universal trends (more micro-oriented policy formulation, globalization, the rise of the flexible service economy and the increasing intertwinement of economic, social and environmental policies) and outlines how the national accounts might be adapted and extended so as to enhance its role as the core information system for policy formulation at the macro- and meso-level.
\end{abstract}

\section{Policy Use of National Accounts in the Netherlands}

Right from the start of national accounting in the Netherlands, its usefulness for economic policy has been borne in mind (see Den Bakker, 1993). In this regard, the national accounts have performed a dual function. First, the accounts, and particularly the main aggregates, serve to monitor the performance of economic policy. Secondly, the data and the underlying accounting framework feed into econometric models that are used for forecasts and for an economic evaluation of alternative policy proposals. Particularly, the models of the so-called Central Planning Bureau (CPB) exert a fairly unique influence.

In the Netherlands, policy-makers and even political parties make a very intensive use of the results of CPB's model simulations. Haffner and Van Bergeijk (1994) conclude: ". . . the impact of econometric models on Dutch policy-makers is very substantial. . . . It is a unique phenomenon indeed that CPB prognoses for employment, income (and its distribution) and the budget deficit play an important role in the election campaigns. Astonishing as this may seem to anyone who has ever built or used economic models, popular trust in the CPB's numerical precision is so great that a predicted difference of a few thousand jobs can become the selling point of an election platform." This conclusion refers to a CPB (1994) analysis of the economic consequences of the election programmes of the five biggest political parties for the 1994 general election. Even the Green Party, after a heavy internal debate about the relevance of an econometric model to the structural reforms they envisaged, did not dare to enter the elections without a stamp of approval from the country's official economic forecast wizards. Some time ago, Verbruggen and Zalm, the then director of this agency (and at present the Dutch Minister of Finance), noted: "Ever since consistent national accounts

Note: The author is head of the National Accounts Department. The views expressed in this paper are his own and do not necessarily reflect the views of his employer. He would like to thank various colleagues, participants in Session I of the IARIW's 24th General Conference and two anonymous referees for their helpful suggestions. 
data were available, the national accounts philosophy has explicitly been incorporated in the CPB models" (Verbruggen and Zalm, 1993, p. 153). They continue: "In addition, at the CPB a lot of energy is spent on making sure that the models can produce the finalised national accounts data for the past. This takes a lot of time, particularly in the case of revisions." However, they also point to an imminent danger of this practice: "In formalising economic theory through mathematical equations, model-builders are inclined to abstract from those aspects for which no data are available."

In the mid-seventies, a new generation of models was developed that incorporated all kinds of variables that were not (yet) available from the national accounts: production capacity, capacity demand for labour, utilisation rates, technical progress and credit worthiness. In the eighties, the micro-theoretical foundation of models has become more important. This stimulated the development of an Applied General Equilibrium model, distinguishing 16 types of households and a classification of labour by sex and skill level.

Regarding the national accounts, Verbruggen and Zalm (1993, pp. 161-62) observe: ". . . the accounting system has increasingly come to describe the transactions of clearly-defined categories of companies, households and authorities, which is crucial for usefully testing behavioural hypotheses and, therefore, for economic modelling in general ... The development of a 'core' Social Accounting Matrix (SAM) with various satellite tables seems very promising as well. ... If the CBS succeeds in implementing these promising ideas, such as the integration of input-output tables and, for instance, socio-economic accounts, labour accounts, financial accounts, capital stock accounts and environmental accounts within an internally consistent national accounts framework (in prices and volumes), then the process of divergence between the national accounts and economic modelling at the CPB could change into a process of convergence ..."

Perhaps, this renewed trend towards convergence between national accounts and economic policy modelling is most clearly demonstrated in a recent letter of the Netherlands government to Parliament. This letter contains the following policy statement: "The Central Planning Office's medium-term surveys, which are carried out prior to a government's term in office and usually half-way through it, will deal more systematically than in the past with environmental indicators as well as economic developments (such as economic growth and employment)." (Tweede Kamer, 1996). The same letter describes the development of the NAMEA, the framework for integrated economic and environmental accounts and indicators, at Statistics Netherlands (cf. Keuning and De Haan, 1997; De Haan and Keuning, 1996). The above statement nicely demonstrates why the NAMEA is considered of use to policy-makers: it yields both relevant aggregate indicators and an accounting framework for use in modelling and policy analyses. In fact, this dual function is the time-honoured "unique selling point" of the national accounts in general.

A similar sentiment was reflected in a paper, presented at a recent international conference dealing with the future of statistics, by the then Minister of Economic Affairs in the Netherlands and two co-authors (Andriessen, Van Sinderen and Van Bergeijk, 1995). This paper concerns the requirements of policymakers and contains a metaphor in which economic policy is viewed as space 
travel, in need of fixed numerical guidelines for good navigation. The authors distinguish on the one hand "earthbound" statistics, for which a reasonably stable demand exists and which are generally accepted, and on the other hand statistical "comets" and "shooting stars," which suddenly attract a lot of attention but for which interest fades away almost as fast as it arises. The authors explicitly rank the national accounts among the former category and remark that ". . the system may well be able to survive the next 500 years." (p. 237).

Comforting as this may seem, the authors certainly do not envisage a system that will survive unchanged. In their view, future economic policy will require national accounts which incorporate new issues (i.a. environment, $R \& D$, schooling and the working of markets), and which are more reliable, more detailed, more transparent, and better internationally comparable. In addition, they are in favour of international competition in the compilation of statistics.

In fact, the Dutch national accounts have become more extensive (see the next sections) and, as a consequence, are now used for a broader range of policy analyses than before. The main advantage of these extended national accounts is that they provide the link between all kinds of social, economic and environmental objectives on the one hand and the "hard-core" financial restrictions on the other hand. Interestingly, the availability of this broad information system has also triggered the interest of some "subject matter" departments within the government (e.g. Environment, Housing); they view it as a framework for their negotiations with the Finance Ministry. Finally, the growing influence of the European Union promotes the use of internationally harmonized data, i.e. the national accounts, in all kinds of (national) policy simulations.

A related trend is the fast increasing use of national accounts for policy at the European Union level. More and more important policy decisions are based on national accounts data; think only of the monitoring criteria (government deficit and debt) used in the Economic and Monetary Union. Interestingly, this also has repercussions on national economic policy in the Netherlands. For instance, for some time past the short-term forecasts on the government deficit have included estimates according to the national accounts definition, whereas longer ago the Ministry of Finance just applied its own definition. In addition, the official State balance sheet is now compiled according to the 1995 European System of Accounts (ESA) (Eurostat, 1996).

This increasing use of national accounts aggregates for policy making ensures that these estimates are more and more subject to scrutiny. In itself this is a welcome development: more interest for the compilation methods from various angles can only lead to quality improvement, especially if these parties have conflicting interests. However, it also means that the underlying concepts of the national accounts come under siege. On the one hand some advocate that, since National Income is often (wrongly) equated with national welfare, this figure should be replaced or supplemented with a single, "better" welfare indicator, such as the so-called Green National Income. On the other hand, users increasingly worry about opaque, analytical constructs in the present accounts, such as the imputed rent for owner-occupied dwellings and the proposed allocation of financial intermediation services indirectly measured (the notorious "FISIM") as an intermediate "use" of various industries. 
It is always hazardous to look more than a year ahead and to imagine how the present-day national accounts should be adapted or extended, in order to cope with the policy demands of, say, the turn of the century and beyond. However, at the same time, the development of new aggregate time-series requires many years, especially if new source data are also needed and if world-wide agreement on scope and definition of the underlying variables must be reached. For that reason, in the next four sections some major trends in socio-economic policy-making are described and it is outlined how the national accounts can be adapted and extended to answer these new demands. Without a pretension to completeness, the following developments will be addressed: (a) the tendency towards a more micro-oriented policy formulation, (b) globalization, (c) the rise of the flexible service economy and (d) the increasing intertwinement of economic, social and environmental policies.

\section{More Micro-Oriented Policy Formulation}

The above-mentioned reflection on the future of statistics (Andriessen, Van Sinderen and Van Bergeijk, 1995) identifies three major developments that will influence the policy demand for statistics. In addition to the process of international (and particularly) European integration and the increasing volatility of policy demands, this concerns the following: "Economic policy at the national level is becoming less macro-oriented in the sense of demand management and optimal control of an economy. The orientation is more decentralised, more sectoral and more directed at institutional arrangements and incentives. ... This does not imply that macro figures are obsolete. On the contrary, they still give a good impression of the state of the economy."

Apparently, these authors, in conformity with many others, call for more detail in the existing statistical information systems and above all for an enhanced micro-macro link. Naturally, this is a time-honoured theme for national accountants, and it was again discussed in a separate session during the IARIW's 1996 General Conference. The outcome of that session was (again) that neither macrodata nor micro-data are sufficient for the demands of most users. In fact, it was argued that micro-data, particularly those for enterprises, are already aggregate "constructs" (that is, aggregated over transactions, establishments, etc.), and that they are prone to many kinds of errors (selective non-response, lack of time and interest with respondents, use of administrative rather than economic concepts, discontinuity, incomparability of reporting practices among industries, etc.), so that macro-editing in addition to micro-editing will always yield a superior statistic. At the same time, it was stressed (a) that the procedures used in macro-editing should be more explicitly documented, and (b) that accounting systems, such as the System of National Accounts (SNA), should minimise the number of analytical constructs that are not in conformity with ". . . the economic agents' perceptions of themselves and their transactions" (Van Bochove and Van Tuinen, 1986, p. 141).

To a larger extent than its predecessors, the 1993 SNA (United Nations et al., 1993) provides an "institutional" description of the economy. This means that the system is not designed with a particular type of analysis in mind, but that it 
is meant to reflect the economic actions of "real-world" actors, such as households, corporations and the government. Yet, the introductory chapter also states, without further justification: "The accounting conventions and valuation methods used at a micro level typically differ from those required by the System." (p. 12). This statement seems to suggest that the national accounts typically refrain from describing everyday economic reality. Fortunately, that is not the case. For instance, both in real world transactions and in the national accounts, the current exchange value ("market price") is widely used. Anyway, the national accounts do not pretend to measure utility.

Yet, according to the SNA (para. 6.85), (almost) all goods and services produced for own final use should be valued at the (basic) prices at which they could be sold if offered for sale on the market. This includes, inter alia, homegrown vegetables, home-knitted sweaters, and the services of owner-occupied dwellings. In fact, this "opportunity cost" pricing is inconsistent with the valuation rules in the rest of the system, for two reasons.

First, if all own-consumed goods and services had actually been marketed, both the prices and the consumed quantities of these (and other) products would have been different, which in turn would have had repercussions on yet other transactions. In essence, this means that in most cases the so-called ceteris paribus assumption does not apply at the meso- or macro-level. Therefore, the eventual impact on the macro-economic aggregates can only be estimated with a formal model. Particularly, this applies to a situation where the budget share of the product concerned is substantial while a large part of total consumption is ownproduced (e.g. housing services). Secondly, whereas the opportunity cost of a subsidized surgical treatment is not included in the macro-economic aggregates, it should also not be attempted to estimate the opportunity cost of eating homegrown vegetables. In reality, only the actual cost of a good or service can be quantified in monetary terms; in case of a purchase, this cost equals the purchase price, and in case of own production, this cost equals the production outlays.

Such a valuation rule would also remedy the anomalous treatment of housekeeping services and such in the present SNA. Contrary to other goods and services, these services are at present not viewed as output within the System. The justification for this treatment is not quite convincing (cf. paras 6.21 and 6.22). In fact, these services are output, just like the result of all other economic activities (cf. paras 6.15 and 6.16 of the SNA). However, as these services are not sold and as their production involves no outlays, other than the purchase of some goods (food, detergents, electrical apparatus, etc.) which have already been included in household consumption expenditure, the net value added of this activity is equal to zero (if the durables involved were not bought on credit). Analogously, Net Domestic Product is not affected by this new treatment, provided that the annual consumption of the stock of durables roughly equals the durables' purchase value in the same year. Needless to say, though, that these services do affect welfare and should be incorporated in a comprehensive national accounting system. This is elaborated in Section 5 below.

Valuing all output produced for own final use at its production costs also implies that the circuitous and unreliable procedure to estimate the value of owneroccupied housing services can be replaced by just adding up the actual costs to 
the owner. Of course, these costs include the fixed capital consumption of the house. These costs also include the mortgage interest, as a remuneration for a financial capital input into production. In general, all interest payments, including the FISIM, are part of production costs, and should be shown as a separate valueadded category. This also applies to government production (except for interest payments on a very exceptional debt from the past, such as a war debt). ${ }^{1}$ Since there is no production without the use of financial assets and since the use of these assets is not free of charge, these costs (e.g. interest) should be explicitly shown as inputs into production (cf. Keuning, 1996; Keuning and Reininga, 1996).

Replacing opportunity cost pricing in the standard national accounts by an outlays-based valuation is but one example of strengthening the micro-macro link (cf. e.g. Ruggles, 1996 for a more extensive review). In general, more attention should be given to strengthening the link between national accounts and business accounting. In that way, national accounts will be able to provide a more straightforward reflection of economic reality. Besides, business accounting practices might benefit from more harmonisation, if only to increase the transparency of the stock markets. Thirdly, such a link may serve the unity of economic science.

In conclusion, three more practical reasons for strengthening the micro-macro link can be mentioned. First, estimating opportunity cost prices for items such as owner-occupied housing services, own-consumed production of (allotment) gardens and wages in kind (subsidized canteen meals and free parking), absorbs a disproportionate amount of statistical resources. This is certainly not matched by the statistical benefits. Secondly, using micro-concepts in the national accounts as much as possible considerably facilitates the linkage of source statistics and the national accounts. In turn, such a link might improve the coverage, relevance and reliability of the source statistics, while at the same time the level of detail and the flexibility of the national accounts increase. Imagine the opportunities if the wealth of information in source statistics can be explored within a consistent, broad information system, tailor-made, and with relatively little effort. Thirdly, in virtually all countries the respondent burden is a hot issue. This burden is aggravated by asking enterprises for data that are not directly available in their own administrations. When Electronic Data Interchange (EDI) is applied for capturing the information, the definition of the variables obtained will anyhow be in accordance with the business administrations' concepts. Converting this information to variables with another definition must then be done within statistical offices. This activity will be quite costly and will always yield more or less arbitrary results, as it is not based on directly observable facts.

The ideas expressed in this section mean that the monetary national accounts become truly monetary accounts. This means a considerable improvement of the transparency of the system and of their usefulness for various economic policy purposes, including international taxation. For, countries contribute money to international organisations, not labour time, free housing services or environmental functions. Related to this, the financial strength of a country is determined

\footnotetext{
${ }^{1}$ Note that if the government leases capital goods, the financial input costs are also (implicitly) included in its (operational lease) intermediate input costs, and thus in government output.
} 
by its Net National Income in monetary terms. In addition, this emphasis on (monetary) transactions in the accounts also fosters a closer (complete?) link between the consumption concept in the national accounts and in the consumer price index (CPI). In turn, economic policy analysis is greatly served if core economic indicators such as GDP volume change and the CPI change are derived from the same analytical framework.

All the same, it should be avoided that, because of this new orientation of the macro-economic statistics, the relationship between the national accounts and welfare measurement becomes even looser than at present. However, before this major other challenge to the national accounts of the future is discussed in Section 5 below, the next two sections touch upon the implications of two important realworld trends: globalization and the rise of the flexible services economy.

\section{Globalisation}

Globalization can be characterized by the increasing geographical divergence of various economic processes which used to occur within the same country, such as:

1. production and consumption,

2. investment and production, and

3. financing and investment.

Especially the de-linking of international commodity and money flows has led to an increasing interdependency of national economic policies. At the same time, deregulation has typically had a detrimental effect on the quality and quantity of source data for the national accounts. Without doubt, this trend has put a greater burden on the national accountants to provide a reliable overview of the functioning of the national economy.

In this respect, some predict the imminent replacement of national accounts by European or even world-wide accounts. Let us not forget, though, that as long as national governments exist that are primarily concerned with the welfare of their population, there will be a national economic policy demanding national accounts. In fact, many policy-makers now turn to the (extended) national accounts to obtain more insight into the strengths and weaknesses of the domestic economy. Moreover, for some time to come, the most important fiscal, social, and environmental policy measures are determined at the national level. Even in Europe, some more water may flow under the bridges before abandonment of the "subsidiarity" principle is considered a realistic option.

Nevertheless, it goes without saying that a growing demand exists for: (a) internationally comparable data, (b) supra-national accounts, and (c) more insights into economic linkages among countries. For all these data sets, the intended world-wide application of the 1993 SNA paves the way. In fact, the very existence of these truly universal guidelines is a major achievement, that perhaps deserves a little more attention among the media and the policy-makers.

In addition, the structure and the classifications of the 1993 SNA will yield a lot more data on international ties than its 1968 predecessor. For instance, reinvested earnings on direct foreign investment will now be shown explicitly. In addition, foreign-controlled enterprises are singled out in the institutional sector 
classification. For that matter, in the Netherlands' accounts, national enterprises with and without foreign affiliates will also be shown separately.

Next, the complete harmonisation between the SNA and the IMF's balance of payments manual-unfortunately, except for the treatment of FISIM (?)-is quite instrumental to a further integration of the national accounts and balanceof-payments statistics. In turn, such an integration is not only efficient, but also enhances the possibility for analysing international economic linkage (e.g. direct foreign investment).

Finally, it is worthwhile to explore the possibilities to compile e.g. crosscountry international trade matrices which are consistent with the (definitive) national accounts of the participating countries. For the first time, such an effort would require international co-ordination of the compilation of national accounts. The U.S. and Canada already have some experience in this field, while in the European Union this subject is under discussion.

\section{The Flexible Services Economy}

Another crucial test for the policy relevance of the national accounts is its ability to cope with the rapidly growing importance of (flexible) services. This coincides with an increasing attention for "human capital" as the decisive production factor. In my view, this mega-trend is not sufficiently reflected in the 1993 SNA's central framework. The present core accounts still distinguish only one type of labour (e.g. in the supply and use tables) and do not even distinguish the employed person as a separate, economically relevant entity. This serious shortcoming is remedied in the Social Accounting Matrix (cf. the SNA's Chapter XX). In general, the integration of disaggregate labour accounts (categorised by e.g. sex, educational level and type of job contract) and national accounts is the most important task ahead once the 1993 SNA has been implemented.

On the other hand, in a rapidly changing economy, the notion of "fixed" capital input becomes less important. In fact, the dividing line between intermediate inputs (including operational lease of fixed assets) and the consumption of fixed capital becomes increasingly blurred. Perhaps, it is preferable to record the consumption of fixed assets within the intermediate input block (as a delivery of the capital goods producing industry to intermediate demand instead of final demand).

At the same time, the core SAM of the future should contain a different industry classification, taking economic homogeneity (financing structure, input and output markets on which the firm operates) rather than technical homogeneity of the production process as a point of departure. For example, "manufacture of fast-moving consumer goods" is probably a more relevant industry than "manufacture of dairy products" or "manufacture of soap, detergents and perfumes".

Analogously, some industries are characterized by a combination of (very) large and (very) small firms. Typically, such groups of firms operate on very different input (capital) and output (consumers) markets. The fact that their output has roughly the same physical characteristics does not warrant their lumping together in a single "industry." For instance, supermarket chains, local grocery shops and ambulant traders all operate in distinctly different industries, although 
they all produce retail services. This is because these three types of retailers use quite diverging marketing instruments and have a quite different access to e.g. organizational know-how and financial capital inputs. ${ }^{2}$ When these activities are classified in different industries, it is also acknowledged that the fact whether or not an establishment is part of a (much) larger enterprise may influence its production technology.

Finally, the measurement of services output itself deserves more attention. In particular, this refers to the estimation of price and volume changes. Again, it is important that for this purpose an economic and not a "technical" classification of services is applied. For instance, a stratification of lodging services into services provided by hotels, motels and youth hostels may be less relevant than a breakdown of lodging services by quality category (one to five stars) or market segment. In addition, the recording of Research and Development expenditures should be reconsidered. Probably, these expenditures are most suitably viewed as work in progress (change in inventories), as long as they have not yet yielded an identifiable economic asset such as a patent (see Bos, Hollanders and Keuning, 1994).

\section{Intertwinement of Economic, Social and Environmental Policies}

The 1993 SNA takes a somewhat ambiguous attitude towards the relevance of GDP and such for the measurement of welfare. A special section on this issue states: "... total welfare depends on many other factors besides the amounts of goods and services consumed." (para. 1.77), but also "The use of one or two aggregates to gauge changes in welfare may be one of the more important uses of the System ..." (para. 1.82). In my view, much confusion would be avoided if it is clearly stated that GDP volume change in itself is not a sufficient indicator to measure welfare change.

This is not to say that the national accounts should refrain from the measurement of social welfare. On the contrary, many welfare attributes can and should be depicted within a more extensive system. Of course, this is a very ambitious objective, so that a flexible approach is required. However, many national statistical systems already collect and publish information on virtually all aspects of welfare. Thus the problem is not so much a lack of information, but a lack of integration of this information within a comprehensive, though flexible statistical information system. This requirement is met by a System of Economic and Social Accounting Matrices and Extensions (SESAME), as sketched in the 1993 SNA (paras 20.29-20.33) and elaborated in Keuning (1996), who has built on earlier work of, among others Stone (1986), Pyatt and Round (1985), and Downey and Thorbecke (1992). ${ }^{3}$

In Chapter I of Keuning (1996), content and purpose of the SESAME are outlined: "A SESAME is a statistical information system in matrix format, from which a set of core economic, environmental and social macro-indicators is derived. The system is driven, to a large extent, by the kind of information required

\footnotetext{
${ }^{2}$ The important role of financial capital inputs into production is elaborated and illustrated in Keuning (1996) and Keuning and Reininga (1996).

${ }^{3}$ Refer to Keuning (1997) for a concise introduction to the SESAME-concept.
} 
for monitoring and policy-making at the macro-level. Although it is impossible to capture socio-economic development in a single indicator, it is equally clear that a prime task of national statistical offices is to comprise the countless numbers they collect to a manageable, "executive" summary. Such a summary typically describes trends in main indicators. At the same time, for analytical purposes a more detailed data framework is required. Obviously, the communication between policy-makers and analysts is optimally served if the core macro-indicators are all derived from an integrated information system such as a SESAME."

Essentially, a SESAME integrates economic, social and environmental accounts and indicators, through a conceptual and numerical linkage of related monetary and non-monetary data. It extends the SAM by integrating related information, in non-monetary units. For instance, compensation of employees by industry and labour category in the SAM is broken down into hours worked and an average hourly wage rate. In turn, these hours worked for payment are related to other time use of the employed persons concerned. Subsequently, time use of the employed persons can be combined with the time use of the other members of the same household (group), to arrive at a comprehensive linkage of (social) time use data and (economic) income figures.

Another example refers to the daily calorie intake, which is an important social indicator in developing countries. This calorie intake can be related to the quantities consumed, which in turn underlie the consumption submatrix in the SAM (Keuning, 1996; Section IV.3.4).

Summarising, the linkages between the monetary accounts and the other accounts in the SESAME are typically established in non-monetary units, such as hours, calories, gigajoules and volume changes. This means that an essentially arbitrary imputation of a hypothetical price to an unpriced flow is avoided. Therefore, a SESAME remains a statistic, and not the outcome of an (implicit) model. ${ }^{4}$

In the Netherlands, this SESAME system is gradually developing. It started with the compilation of a pilot SAM (Timmerman and Van de Ven, 1994) and a National Accounting Matrix including Environmental Accounts (NAMEA) (De Haan and Keuning, 1996; Keuning and De Haan, 1997). In this NAMEA-framework, environmental accounts and summary indicators in physical units are linked to a conventional national accounts matrix. Both the SAM and the NAMEA are now an integral part of the annual national accounts in the Netherlands, and particularly the NAMEA is frequently used for economic policy purposes in the Netherlands.

A recent joint letter of the Minister of Economic Affairs and the Minister of Housing, Physical Planning and Environment to Parliament reports on this as follows: "At the macro-level, too, (national) income cannot be regarded as equivalent to (national) welfare. Developments in welfare are determined by many factors: not only the development of the national income, but also changes in available environmental functions, the distribution of income, employment and health. It is therefore important to have information systems at our disposal that yield an integrated picture of the connections between various aspects of welfare.

${ }^{4}$ Refer to Richter (1994) for a lucid review of the important and intricate distinction between statistics and modelling. 
Statistics Netherlands has already started setting up an integrated information system in the form of environmental accounts (NAMEA) and labour accounts (SAM) linked to the National Accounts. This should finally result in an extensive System of Economic and Social Accounting Matrices with Extensions (SESAME)." (Tweede Kamer, 1996.)

Concerning an national income estimate adjusted for environmental degradation (the so-called Green National Income), the Ministers state: "In reality, the Green National Income does not exist, and therefore it can only be determined by model calculations. ... Since the results of such calculations are highly sensitive to assumptions, model specifications, and the environmental standards applied, many alternative Green National Incomes can be calculated. It is unlikely that such calculations would ever produce one uncontestable figure. It is not clear in advance whether a recalculated income figure concerning a past year is useful enough to warrant the extensive research needed. In our opinion, it would be more interesting and practical to take a more future- and policy-oriented approach to meet the demand for a Green National Income. This can be realized by assessing the possible medium- and long-term size of the national income, in the event of a future decrease in the environmental pressure arising from politically determined environmental standards." (Tweede Kamer, 1996).

Meanwhile, the NAMEA and the SAM have also been combined in a single framework (Keuning and Timmerman, 1995). Present development of the Netherlands' SESAME focuses on linking the SAM to sociodemographic accounts and on incorporating more detailed accounts on social benefits and its beneficiaries. In addition, work is continuing on the inclusion of time use accounts (cf. Kazemier and Exel, 1992) and a R\&D-module (Bos, Hollanders and Keuning, 1994). Finally, from 1996 onwards Statistics Netherlands has published an annual review of the performance of the Dutch economy, including social and environmental developments. The very first table of this publication shows the changes of the "core" economic, social and environmental indicators, while the underlying trends are highlighted in the remainder of the book. For the time being, though, the data underlying some of the core social indicators in the first table (life expectancy, health situation, criminality) have not yet been integrated into a SESAME.

Compilation of a SESAME ensures that unpriced welfare attributes are not overlooked in the national accounts and in the subsequent economic policy analyses. This obviates the need to insert such attributes as a kind of cuckoos in the GDP nest. As a consequence, in the accounts themselves a tighter micro-macro link can be maintained, i.a. by valuing all output at (basic) market prices or at actual production outlays. This valuation principle yields the most meaningful and transparent measure of net economic value at current prices, in my view.

Concerning the aggregate measure of volume change in the economy, matters are far more complicated. In the first instance, one might imagine that for that purpose the weights of unpriced commodities are based on some sort of opportunity costs. However, this is only a very partial and even biased solution to the more general problem that actual prices (including "zero" prices) are often not the "right" prices, from a social welfare point of view. For priced commodities as well, the deviation between actual prices and "right" prices can be quite 
substantial, due to the existence of consumer surpluses, price distortions (e.g. subsidies, rationing), sub-optimal income and wealth distributions, and differences between individual and social welfare (illegal transactions, "conspicuous" consumption). It is anyhow questionable whether "correct", objective weights can be computed by a statistical office.

In these circumstances, national statistical institutes may adopt the following strategy:

1. Accept that welfare change cannot be monitored on the basis of a single indicator (such as GDP volume change).

2. Try to design a list of core welfare indicators which (a) each shed light on an important aspect of welfare, and (b) are based on observable facts and are aggregated on the basis of undisputed weights (e.g. total productive time use, pressure indicators by environmental problem, average number of years of schooling).

3. Use market prices (and total production outlays for government services and own-consumed production) as weights for computing GDP volume change.

4. Communicate more explicitly to the users and to the public at large that GDP volume change yields only a very partial insight into welfare change.

At the same time, it might be a worthwhile economic research project to construct a model that simulates the functioning of an economy in which all goods and services are priced at their opportunity costs. Of course, in such a model the behavioural reactions to such drastic price changes ought to be incorporated.

\section{Conclusions And Recommendations}

Right from the start of national accounting, a close link with the demands of socio-economic policy analysis has existed. In the Netherlands, the official government models exert relatively much influence on the design of socio-economic policy. At present, the development of the Dutch national accounts framework (application of Social Accounting Matrix and the environmental module NAMEA) and the development of the modelling framework (application of Applied General Equilibrium models and the incorporation of environmental issues) move in parallel.

The principal strength of national accounts is probably that they provide both core indicators for a quick glance at socio-economic development and an underlying analytical framework. In this way, all prospective policy analyses yield alternative values for the same variables as are used for monitoring the past.

The policy relevance of national accounts has been enhanced by the existence of commonly accepted international guidelines for their compilation. The 1993 SNA is a major step forward in this regard, not only because of its world-wide implementation, but also because of its broadened scope, including, in particular, the relations between stock and flow accounts and full-fledged balance sheets.

This augmented use of national accounts gradually leads to more interest for the underlying concepts. For instance, it is questioned whether present-day national accounts are sufficiently suited to shed light on the mega-trends of globalization and the transformation into a flexible service economy. Above, it has been argued that globalization may not require many new concepts, apart from the ones 
that have already been incorporated in the 1993 SNA but are not yet implemented. Rather, it calls for more co-ordination when compiling the accounts. At the national level, this refers to the attunement of balance-of-payments statistics and the national accounts. At the international level, the organisational feasibility of reconciling nationally deviating estimates on bilateral (trade) flows should be investigated.

The trend towards a flexible service economy and the concomitant shift to human capital as the prime determinant of competitiveness requires, at the very least, an integration of detailed labour accounts (by sex, by educational level, by type of job contract, etc.) and the national accounts. Moreover, the technical, engineering characteristics of production processes become less and less relevant. As outlined in Section 4 above, this requires a new concept of capital input in production, a different industry classification and a reconsideration of the establishment unit.

Finally, policy-makers are keen that the results are not sensitive to all kinds of quite arbitrary imputations. In general, the transparency of the accounting system is sometimes questioned (in case of e.g. the proposals for allocating FISIM, the imputed rent for owner-occupied housing, and the estimation method for the consumption of fixed capital). On the other hand, time and again a demand is expressed for incorporating welfare aspects that are thus far not covered in the system (environmental degradation, productive time use within the household, etc.).

The best way to meet these apparently conflicting demands is a two-tier strategy:

1. Establish a tighter micro-macro link in the monetary accounts, and

2. Extend the system with non-monetary accounts and indicators, to arrive at a full-fledged System of Economic and Social Accounting Matrices and Extensions (SESAME).

The first tier of this strategy means that concepts, statistical units, etc. in the monetary accounts are closely in line with the perceptions of the economic subjects themselves. In this regard, more attention should also be given to the harmonization of business accounting regulations (e.g. at the European level) and national accounts guidelines such as the SNA and the European System of Accounts (ESA '95). However, the objective of welfare measurement should not be achieved through a (necessarily half-hearted) attempt to mix actual market prices and fictive, opportunity cost valuation in a single aggregate (GDP).

That purpose is served by the second tier of the strategy, the linkage of these purely monetary accounts to non-monetary accounts in the SESAME. Thus a SESAME does not insert analytical ("functional") elements into the monetary system (as is done at present), nor does it relegate social and environmental data to separate statistics or to a series of mutually unconnected "satellite" systems for specific subjects. In a SESAME, the institutional units (households, government units, corporations) in the monetary system are linked to other kinds of units at a meso-level [groups of (employed) persons, product groups, etc.]. Then, to give but an example, the consumption expenditure of certain product groups by certain household groups is split into a price and volume component, and then this consumption volume (change) can be related to all kinds of welfare-related 
units, such as education, health status and waste generation. Finally, these nonmonetary variables are aggregated to meaningful macro-indicators for various welfare attributes. Anyhow, national statistical institutes should communicate more explicitly that only a set of indicators can cover the most important welfare aspects. Further aggregation always requires a political judgement.

Compilation of a SESAME essentially boils down to making a better use, through integration, of data that are already collected by statistical offices. This will produce information that is (a) more relevant (interrelations between social, economic and environmental developments can be better monitored and analyzed with a single information system), (b) more reliable (more logical identities have been checked), and (c) more efficiently compiled (integration requires co-ordination, and co-ordination promotes efficiency). Flexiblity is enhanced by enabling custom-made breakdowns of (parts of) the standard SESAME. Besides, integrating statistics in an information system improves both the quality and the level of detail of very timely, preliminary estimates. This is demonstrated in the Netherlands by the methodology for the quarterly accounts and the quarterly flash estimates (Algera and Janssen, 1991; Ouddeken and Zijlmans, 1991).

Another way to express the above two-tier strategy is by saying that the monetary national accounts will deal with the (direct) costs. Contrary to benefits, these can namely be quantified in monetary terms. Benefits can only be expressed in (a range of ) non-monetary units. Compilation of an extended national accounting system then serves to provide socio-economic policy with a framework for monitoring and analysing not only the costs, but also the benefits and the externalities.

\section{BIBLIOGRAPHY}

Algera, S. B. and R. J. A. Janssen, The Development of Short-term Macro-economic Statistics, in CBS, Select 7, Statistics Netherlands, Voorburg/Heerlen, 1991.

Andriessen, J. E., J. van Sinderen, and P. A. G. van Bergeijk, Requirennents of Policy Makers, in Z. Kenessey (ed.), The Future of Statistics; an International Perspective, International Statistical Institute, Voorburg, 1995.

Den Bakker, G. P., Origin and Development of Dutch National Accounts, in W. F. M. de Vries, G. P. den Bakker, M. B. G. Gircour, S. J. Keuning, and A. Lenson (eds.), The Value Added of National Accounting, Statistics Netherlands, Voorburg/Heerlen, 1993.

Van Bochove, C. A. and H. K. van Tuinen, Flexibility in the Next SNA : the Case for an Institutional Core, The Review of Income and Wealth, Series 32, Number 2, June 1986.

Bos, F., H. Hollanders, and S. J. Keuning, A Research and Development Module Supplementing the National Accounts, The Review of Income and Wealth, Series 40, Number 3, September 1994.

$\mathrm{CPB}$, Vijf verkiezingsprogramma's: economische gevolgen van voorgenomen beleid (Five Election Programmes: Economic Consequences of Intended Policies), Central Planning Bureau, The Hauge, 1994.

Downey, R. A. and E. Thorbecke, Socio-economic Structure and Performance up to 1982/83: The Initial Conditions, in E. Thorbecke and associates, Adjustment and Equity in Indonesia, Development Centre of the Organisation for Economic Co-operation and Development, Paris, 1992.

Eurostat, European System of Accounts (ESA 1995), Eurostat, Luxembourg, 1996.

De Haan, M. and S. J. Keuning, Taking the Environment into Account; The NAMEA-Approach, The Review of Income and Wealth, Series 42, Number 2, June 1996.

Haffner, R. C. G. and P. A. G. van Bergeijk, The Economic Consequences of Dutch Politics, De Economist, Volume 142, Number 4, 1994.

Kazemier, B. and J. Exel, The Allocation of Time in the Netherlands in the Context of the SNA : A Module, National Accounts Occasional Paper Series, No. NA-052, Statistics Netherlands, Voorburg, 1992. 
Keuning, S. J., Accounting for Economic Development and Social Change, IOS Press, Amsterdam, 1996.

, SESAME: an Integrated Economic and Social Accounting System, International Statistical Review, Volume 65, Number 1, 1997.

Keuning, S. J., and M. de Haan, Netherlands: What's in a NAMEA? Recent Results, in P. Bartelmus, C. Stahmer and K. Uno (eds.), Environmental Accounting in Theory and Practice, Kluwer Academic Publishers, Dordrecht, The Netherlands, 1997.

Keuning, S. J. and T. Reininga, Accounting for the Use of Financial Capital as an Input in Production, National Accounts Occasional Paper Series, No. NA-085, Statistics Netherlands, Voorburg, 1996.

Keuning, S. J., and J. G. Timmerman, An Information System for Economic, Environmental and Social Statistics: Integrating Environmental Data into the SESAME, in Conference Papers from the Second Meeting of the London Group on Natural Resources and Environmental Accounting, U.S. Bureau of Economic Analysis, Washington D.C., 1995.

Ouddeken, F. E. M. and G. M. Zijlmans, The Use of Tendency Surveys in Extrapolating National Accounts, The Review of Income and Wealth, Series 37, Number 3, September 1991.

Pyatt, G. and J. Round, Social Accounting Matrices: A Basis for Planning, World Bank, Washington D.C., 1985.

Richter, J., Use and Misuse of National Accounts from a Modeling Perspective, The Review of Income and Wealth, Series 40, Number 1, March 1994.

Ruggles, R. The United Nations System of National Accounts and the Integration of Micro and Macro Data, in J. W. Kendrick (ed.), The New System of National Accounts, 387-416, Kluwer Academic Publishers, Boston, 1996.

Stone, R., Social Accounting: the State of Play, Scandinavian Journal of Economics, Volume 88, 453$72,1986$.

Timmerman, J. and P. van de Ven, A Social Accounting Matrix for the Netherlands: Concepts and Results, National Accounts Occasional Paper, No. NA-068, Statistics Netherlands, Voorburg, 1994.

Tweede Kamer (Second Chamber of the Netherlands' Parliament), Action Plan for Green National Accounting, Tweede Kamer, The Hague, 1996.

United Nations, Eurostat, International Monetary Fund, Organisation for Economic Co-operation and Development, and World Bank, System of National Accounts 1993, Series F, No. 2, Rev. 4, United Nations, New York, 1993.

Verbruggen, J. P. and G. Zalm, National Accounts and Modelling at the Central Planning Bureau, in W. F. M. de Vries, G. P. den Bakker, M. B. G. Gircour, S. J. Keuning, and A. Lenson (eds.), The Value Added of National Accounting, Statistics Netherlands, Voorburg/Heerlen, 1993. 